\title{
Enhancement of PLA-PVA Surface Adhesion in Bilayer Assemblies by PLA Aminolisation
}

\author{
Alina Tampau ${ }^{1}$ (D) $\cdot$ Chelo González-Martínez $^{1} \cdot$ António A. Vicente $^{2} \cdot$ Amparo Chiralt $^{1}$
}

Received: 6 March 2020 / Accepted: 3 June 2020 / Published online: 18 June 2020

(C) Springer Science+Business Media, LLC, part of Springer Nature 2020

\begin{abstract}
Poly(lactic acid) (PLA) and poly(vinyl alcohol) (PVA) present complementary barrier properties, and their combination in multilayer assemblies (laminates) could provide materials with more effective barrier capacity for food packaging purposes. However, their low chemical affinity compromises adequate polymer adhesion. Surface free energy modification of thermoprocessed PLA films through treatment with 1,6-hexanediamine was used to enhance adhesion with polar PVA aqueous solutions. Treatments of 1 and $3 \mathrm{~min}$ increased the polar component of the solid surface tension, while treatments above 10 min provoked a corrosive effect in the films' structure. Extensibility analyses of PVA solutions loaded with carvacrol (15 wt.\%) and different Tween 85 ratios on PLA-activated surfaces allowed the selection of the 1-min aminolysed surface for obtaining PLA-PVA bilayers, by casting PVA solutions on the PLA films. This study revealed that despite aminolisation enhancing the PLA surface affinity for aqueous PVA solutions, casting-obtained bilayers presented limited oxygen barrier effectiveness due to heterogeneous thickness of PVA layer in the laminates.
\end{abstract}

Keywords Aminolisation $\cdot$ Surface activation $\cdot$ Poly (lactic acid) $\cdot$ Poly (vinyl alcohol) $\cdot$ Carvacrol $\cdot$ Bilayer assembly

\section{Introduction}

Biodegradable polymers have generated an increased interest in the current packaging field, as the massive use of conventional petroleum-based plastics has led to a negative environmental impact worldwide. Some biobased aliphatic polyesters, such as the polylactides, constitute a very promising group of materials for applications in the packaging area (Petersen et al. 1999).

Alina Tampau

altam@upv.es

Chelo González-Martínez

cgonza@tal.upv.es

António A. Vicente

avicente@deb.uminho.pt

Amparo Chiralt

dchiralt@tal.upv.es

1 Instituto Universitario de Ingeniería de Alimentos para el Desarrollo, Ciudad Politécnica de la Innovación, Universitat Politécnica de Valencia, Camino de Vera, s/n, 46022 Valencia, Spain

2 CEB - Centre of Biological Engineering, University of Minho, Campus de Gualtar, 4710-057 Braga, Portugal
Poly(lactic acid) (PLA) is biocompatible (Food and Drug Administration approved) (Muller et al. 2017a), compostable (Farrington et al. 2005), and made from renewable sources. PLA presents potential as packaging material, as it can produce highly transparent, rigid films that exhibit low water vapour permeability (WVP) (Bonilla et al. 2013; Collazo-Bigliardi et al. 2018). Nevertheless, PLA also presents shortcomings, as it exhibits mechanical fragility/brittleness and limited oxygen barrier capacity (Bonilla et al. 2013).

A useful approach to offset drawbacks of individual films is by emulating the multilayer structure of commercial films. These are currently made of several sheets of polymers ( 3 to 12 layers according to http://polymerdatabase.com/), imparting complementary properties to the final material (e.g. European Patent EP0175451A2, Hsu and Guckenberger 1985). Some layers provide moisture resistance, while others act as gas barriers or provide mechanical support, creating materials more suitable for the intended applications.

This strategy of pairing polymer sheets is already ongoing in the field of biopolymers. Several authors have reported obtaining multilayers with improved physical properties, based on starch and polyester combinations. Requena et al. (2018) obtained bilayers by thermo-sealing cassava starch sheets, and polylactic acid-polyhydroxybutyrate-co- 
hydroxyvalerate blend films, with low WVP and good oxygen barrier capacity. Muller et al. (2017a) also obtained bilayer assemblies from thermo-processed cassava starch and amorphous PLA with improved barrier capacity with respect to the corresponding monolayers. Rhim et al. (2006) developed multilayer films based on a middle sheet of soy protein isolate (SPI) and exterior layers of polylactide obtained by casting. The tensile strength and barrier properties of the laminates also benefited from pairing the two polymers.

Poly(vinyl alcohol) (PVA) is a polar biopolymer with complementary barrier properties with respect to PLA, since its films possess a high barrier capacity to oxygen, with good tensile strength and flexibility (Cano et al. 2015). PVA has already been approved by the USDA to be used in the packaging of meat and poultry products (DeMerlis and Schoneker 2003). However, PVA exhibits high WVP due to its hydrophilic nature. Thus, the laminated assembly with hydrophobic polymer sheets, such as PLA, could yield a multilayer material with enhanced mechanical and barrier features.

One possible strategy to obtain multilayer films is the casting of a polymeric solution on the surface of another polymeric layer support. This method requires a good extensibility of the solution on the polymeric film, which is greatly affected by the surface interactions of the polymer solution with the supporting polymer that, in turn, depends on the molecular interactions between the components in the solution and those on the contact surface (Sapper and Chiralt 2018). However, when using polymers with complementary properties, such as PVA and PLA, these are hydrophilic and hydrophobic in nature, respectively. Therefore, chemical affinity between them or their solutions is low, which compromises the surface interactions to obtain adequate polymer adhesion. To address this shortcoming, a potential strategy is the functionalisation of the PLA surface through the aminolisation technique. This method uses a diamine solution to introduce radicals carrying free amino moieties onto the surface of the PLA film (Zhu et al. 2002). The ester (-COO-) groups in the polylactic acid chain would interact with one of the diamine's $-\mathrm{NH}_{2}$ groups forming a covalent bond ( $\mathrm{O}=\mathrm{C}-\mathrm{NH}-)$ (Fig. 1). Thus, the diamine's structure carrying a free $-\mathrm{NH}_{2}$ moiety would become attached to the polymer surface. The surface modifications in the hydrophilic-lipophilic balance produced by the diamine can easily be monitored by observing the change in the surface energy components, through contact angle measurement. Then, the positively charged amino moieties (activated by immersion in a hydrochloric solution) could interact with a negatively charged polymer (such as partially acetylated PVA) in aqueous solution, generating a well-adhered coating on top of the PLA support material. This surface modification approach has found applications not only in constructing layer-by-layer assemblies for food coating application (Carneiro-da-Cunha et al. 2010; Pinheiro et al. 2012; Medeiros et al. 2012; Medeiros et al. 2014; Fabra et al. 2016) but also in live cell immobilisation on the activated polyester surface (Zhu et al. 2002; Noel et al. 2013). In the previous studies for food packaging applications (Medeiros et al. 2012; Medeiros et al. 2014; Fabra et al. 2016; Souza et al. 2018), the aminolysis functionalisation technique was applied on a non-biodegradable polymer, polyethylene terephthalate (PET), to increase the adhesion of subsequently applied layers of polysaccharides or proteins containing active molecules. No previous aminolisation studies on biodegradable polymeric supports to this end have been found.

The addition of antimicrobial or antioxidant molecules into the multilayer structure could provide additional benefits when used as packaging material, exerting an active protection on the packaged foodstuffs. Several studies have been carried out using different polymers and active compounds to obtain antimicrobial materials for food packaging. Anwar et al. (2018) reviewed previous studies, analysing different incorporation methods (direct mixing, polishing, and encapsulation) of active compounds into the polymeric material in this packaging-making concept.

Carvacrol (CA) is a natural monoterpenoid present as a main constituent in the essential oils of oregano or thyme (Burt 2004; Can Baser 2008). It has proven antimicrobial and antioxidant effects, as reported by many authors (Kamimura et al. 2014; Mascheroni et al. 2011; Ramos et al. 2014). The inclusion of CA in a carrier polymeric matrix could be a useful way to deliver its effects (Turek and Stintzing 2013). In this sense, previous studies reported very slow-release kinetics of these kinds of compounds from PLA films (Muller et al. 2017b), whereas their encapsulation in more hydrophilic polymers (zein, chitosan, cassava, and corn starch) favours the release, providing greater effectiveness as antimicrobial agents (Fabra et al. 2016; Muller et al. 2017b; Tampau et al. 2018).

Multilayer assemblies could incorporate the active compound into the polymer layer, where the active compound is more effectively delivered in the target food to exert the antimicrobial or antioxidant action. The incorporation of the active compound in the polymer matrix modified the barrier and

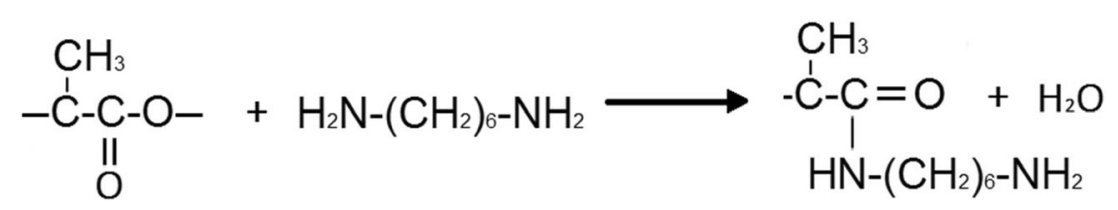

Fig. 1 Mechanism of aminolisation by 1,6-hexanediamine, occurring at the polylactide's surface 
mechanical properties of the film to a different extent, as reported by Requena et al. (2018) and Tampau et al. (2018) when carvacrol was incorporated into starch-polyester-blend bilayers and starch-PCL-starch multilayers, respectively.

Obtaining polyester sheets by the usual thermo-processing and casting on their surface a film-forming solution with a polar polymer, such as PVA, with complementary barrier properties, is a feasible process to prepare laminates for food packaging purposes. The incorporation of the active compounds, such as carvacrol in the film-forming solution, allows to avoid the thermal treatment of the active, preserving better its properties.

The aim of this study was to analyse the effect of the aminolisation of thermo-processed PLA films on their surface energy (polar and dispersive components) and its impact on the extensibility of PVA aqueous solutions containing or not $\mathrm{CA}$ as active component, and surfactant. The functional properties of the bilayer assemblies as packaging material were also characterised to analyse the aminolisation effect on the laminate properties.

\section{Materials and Methods}

\section{Materials}

PLA 4060D (density $1.24 \mathrm{~g} / \mathrm{cm}^{3}$; D-isomer content $12 \% \mathrm{wt}$ ) was acquired from Natureworks (Minnetonka, MN, USA) in the form of pellets. 1,6-diamino-hexane (for synthesis) was purchased from Merck Millipore Corporation (France), and 2-propanol, hydrochloric acid and dimethyl sulfoxide were from PanReac AppliChem (Castellar del Vallès, Barcelona, Spain). Ethyl acetate was acquired from Indukern (El Prat de Llobregat, Barcelona, Spain). PVA ( $\mathrm{M}_{\mathrm{w}} 13,000-23,000$; 87$89 \%$ hydrolysed), polyoxyethylene sorbitan trioleate Tween $85(\mathrm{~S})$, carvacrol, and phosphorous pentoxide $\left(\mathrm{P}_{2} \mathrm{O}_{5}\right)$ were purchased from Sigma-Aldrich (Sigma-Aldrich Chemie, Steinheim, Germany). Ultrapure water (resistivity of 18.2 $\mathrm{M} \Omega \mathrm{cm}$ ) was prepared using the Milli Q Advantage A10 equipment from Millipore S.A.S., Molsheim, France.

\section{Mono- and Bilayer Preparations}

\section{PLA Support Monolayers}

Polylactic acid sheets were obtained by compression moulding. To this end, $4 \mathrm{~g}$ of the amorphous PLA pellets was placed on Teflon sheets in a hot plate press (Model LP20, Labtech Engineering, Thailand) and preheated for $4 \mathrm{~min}$ at $160{ }^{\circ} \mathrm{C}$. Compression was applied for $4 \mathrm{~min}$ at 100 bar and $160{ }^{\circ} \mathrm{C}$, followed by a cooling cycle of $3 \mathrm{~min}$. The films thus obtained were kept in a desiccator with $\mathrm{SiO}_{2}$ until used.

\section{PLA/Aminolisation}

Surface aminolisation of PLA was carried out as described by Zhu et al. (2004). Briefly, the PLA films were immersed in ethanol-water $(1: 1 \mathrm{v} / \mathrm{v})$ solution for $2 \mathrm{~h}$ at room temperature to remove possible fatty residues adhered during manipulation. Afterwards, they were washed with abundant deionised water and dried in a vacuum oven at $30^{\circ} \mathrm{C}$ for $24 \mathrm{~h}$, until constant weight. The sheets were then immersed for different times (1, $3,5,10,15$, and $30 \mathrm{~min}$ ) at $50{ }^{\circ} \mathrm{C}$ in $0.25-\mathrm{mol} \mathrm{L}^{-1} 1,6-$ hexanediamine solution in 2-propanol. A control sample immersed only in 2-propanol at $50{ }^{\circ} \mathrm{C}$ for the different times was also prepared. The treated surfaces were thoroughly rinsed with deionised water for $24 \mathrm{~h}$ at room temperature to remove traces of the unreacted diamine and dried in a vacuum oven $\left(30{ }^{\circ} \mathrm{C}\right.$ for $\left.24 \mathrm{~h}\right)$. Similarly to Pinheiro et al. (2012) and Medeiros et al. (2012), the aminolised sheets were then immersed in a $0.1-\mathrm{mol} \mathrm{L}^{-1}$ hydrochloric acid solution for $3 \mathrm{~h}$ at room temperature, in order to positively charge the amino moieties grafted onto the surface. Then, the films were washed with abundant deionised water and dried again under vacuum at $30{ }^{\circ} \mathrm{C}$ for $24 \mathrm{~h}$. The weight and thickness (measured by a Palmer digital micrometre from Comecta, Barcelona, Spain) of the dried materials were recorded. All the dried PLA films (treated and activated) were then stored in desiccators with $\mathrm{SiO}_{2}$ until their use.

\section{PVA/Incorporation of Actives}

PVA film-forming dispersions (FFDs) were prepared by dissolving the polymer (15 wt.\%) in ultrapure water, under heating at $80{ }^{\circ} \mathrm{C}$ and constant magnetic stirring for $1 \mathrm{~h}$. Carvacrol (CA) was added at 15 wt.\% with respect to the PVA content. These aqueous formulations were prepared with and without Tween 85 surfactant (S), using three different S:CA weight ratios: $0.3: 100,0.4: 100$, and 0.5:100. The first ratio value was considered based on an expected CA droplet diameter of $10 \mu \mathrm{m}$ (Tampau et al. 2020) and a surfactant excess surface concentration of $5 \mathrm{mg} / \mathrm{m}^{2}$, in the range of the previously reported values (Owusu Apenten and Zhu 1996). This initial ratio was increased in order to determine possible benefits of an excess of surfactant on the wettability of PVA solutions. Afterwards, the dispersions were homogenised at 12,000 rpm for $3 \mathrm{~min}$ using an Ultra Turrax rotor-stator homogeniser (Model T25D, IKA Germany). CA-free FFDs containing only PVA were also prepared as control. The FFDs were degassed under vacuum and allowed to rest at room temperature for $24 \mathrm{~h}$ to check their stability.

\section{Bilayer Assembly}

The bilayer assemblies were obtained by coating the support PLA sheet (aminolised or not) with the selected PVA 
solutions. For this purpose, the aqueous solution, equivalent to $1.5 \mathrm{~g}$ of PVA polymer, was spread onto each PLA sheet by means of a manual spiral bar coater (100 $\mu \mathrm{m}$, Elcometer, UK). This implied a PVA/PLA wt. ratio of about 0.35 in the bilayer. The bilayers were allowed to dry at $21{ }^{\circ} \mathrm{C}$ and $55-60 \%$ relative humidity $(\mathrm{RH})$. Then, the dry materials were conditioned at $25{ }^{\circ} \mathrm{C}$ in desiccators with saturated solutions of $\mathrm{Mg}\left(\mathrm{NO}_{3}\right)_{2}$ ensuring 53\% RH, until their characterisation. The weights of the films were carefully recorded before and after the coating application to check the polymer wt. ratio. The prepared bilayers were labelled based on the untreated (PLA) or aminolised (am-PLA) support, and the applied PVA coating, carrying or not active (C) and/or surfactant (S) (e.g. am-PLAPVA-C/S describes the bilayer obtained with PLA aminolised support and PVA layer containing both CA and S).

\section{Analyses of Surface Properties}

\section{Surface Free Energy of PLA Films}

The surface free energy of the PLA sheets was assessed preand post-aminolisation using the sessile drop method (Kwok and Neumann 1999) by means of a contact angle metre (OCA 20 Dataphysics, Filderstadt, Germany). This involved measurement of the contact angle $\theta$ between the analysed surface and different standard liquids of different polarities and known surface tensions. Dimethylsulfoxide (DMSO), ultrapure water, and ethyl acetate were used for this purpose. Their surface tension and dispersive and polar components are, respectively, $44.0,36.0$, and $8.0 \mathrm{mN} \mathrm{m}^{-1}$ for DMSO; $72.8,22.1$, and $50.7 \mathrm{mN} \mathrm{m}^{-1}$ for water; and 23.9, 23.9, and $0.0 \mathrm{mN} \mathrm{m}^{-1}$ for ethyl acetate (www.accudynetest.com/ surface_tension_table.html). According to Hejda et al. (2010), the surface free energy of the solid $\left(\gamma_{\mathrm{S}}\right)$ can be expressed by using Young's equation (Eq. 1):

$\gamma_{\mathrm{S}}=\gamma_{\mathrm{SL}}+\gamma_{\mathrm{L}} \cdot \cos \theta$

where:

- $\gamma_{\mathrm{SL}}$ is interfacial tension solid-liquid,

- $\gamma_{\mathrm{L}}$ is the surface tension of the liquid, and

- $\theta$ is the contact angle formed between the liquid-air interface and the solid surface.

If the polar and dispersive components acting at the interfacial tension are considered, this surface interaction can be described by using Eq. 2 . Then, from the values of the contact angle of pure solvents, with known dispersive $\left(\gamma_{\mathrm{L}}^{d}\right)$ and polar $\left(\gamma_{\mathrm{L}}^{p}\right)$ components, on a determined surface, the plot of the variables according to Eq. 2 permits the estimation of dispersive $\left(\gamma_{\mathrm{S}}^{d}\right)$ (from the intercept of linear plot) and polar $\left(\gamma_{\mathrm{S}}^{p}\right)$ (from the slope of linear plot) components of the surface free energy (Sapper and Chiralt 2018). Solvent drops of $2 \mu \mathrm{L}$ were placed on the PLA surface, and the contact angle was determined at contact times of 0,30 , and $60 \mathrm{~s}$. Ten replicates of the angle measurements were carried out at room temperature (21 $\pm 1{ }^{\circ} \mathrm{C}$ ) for each film sample and solvent.

$$
\frac{1+\cos \theta}{2} \cdot \frac{\gamma_{\mathrm{L}}}{\sqrt{\gamma_{\mathrm{L}}^{d}}}=\sqrt{\gamma_{\mathrm{S}}^{p}} \cdot \sqrt{\frac{\gamma_{\mathrm{L}}^{p}}{\gamma_{\mathrm{L}}^{d}}}+\sqrt{\gamma_{\mathrm{S}}^{d}}
$$

\section{Surface Tension of PVA Solutions}

All PVA solutions were characterised in terms of their liquidvapour surface tension $\left(\gamma_{\mathrm{LV}}\right)$ using the same equipment as described for the contact angle measurement. The surface tension was estimated by applying the pendant drop method, using the Laplace-Young approximation, as described by Ribeiro et al. (2007) and Carneiro-da-Cunha et al. (2009). Briefly, $10-12-\mu \mathrm{L}$ drops of the PVA solutions were suspended at the flat end of a vertical needle, and with the equipment's image processing software, the $\gamma_{\mathrm{LV}}$ was determined. At least thirty measurements at room temperature (21 $\pm 1^{\circ} \mathrm{C}$ ) were taken for each solution.

\section{Wettability of PVA Solutions on PLA Surface}

Wettability of the different PVA solutions (containing or not $\mathrm{CA}$ and S) was determined on the PLA film surface (aminolised or not). Wettability is assessed by calculating the spreading coefficient $\left(W_{\mathrm{s}}\right)$ (Eq. 3$)$ that represents the balance of the adhesion $\left(W_{\mathrm{a}}\right)$ and cohesion $\left(W_{\mathrm{c}}\right)$ works, as a function of the surface tension of the different PVA solutions and their contact angle on the PLA films (Eq. 4) (Sapper and Chiralt 2018). This parameter only yields a negative or zero value. The closer the value of $W_{\mathrm{s}}$ is to zero, the better the surface will be coated.

$W_{\mathrm{s}}=W_{\mathrm{a}}-W_{\mathrm{c}}$

$W_{\mathrm{s}}=\gamma_{\mathrm{L}}(\cos \theta-1)$

To this end, the measurement of the contact angle between PVA solutions and PLA films was taken, by using the sessile method described above. Ten measurements were carried out for each solution.

\section{Surface Microstructure}

The surface morphology of control and treated PLA was analysed by using field emission scanning electron microscopy (FESEM Ultra 55, Zeiss, Oxford Instruments, UK). For this purpose, the surface of the monolayers was observed without any additional treatment, whereas bilayers were previously cryo-fractured by immersion in liquid nitrogen to 
allow for cross-section view. Samples were mounted with carbon tape on stubs, and after sputtering with platinum in an EM MED020 (Leica Microsystems, Germany), they were observed under an accelerating voltage of $1 \mathrm{kV}$.

\section{Analysis of Functional Properties of Bilayer films}

\section{Water Vapour and Oxygen Permeability}

WVP of bilayers was assessed at $25{ }^{\circ} \mathrm{C}$ and $53-100 \%$ RH gradient, using the ASTM E96-95 gravimetric method (ASTM 1995) and considering the modification proposed by Gennadios et al. (1994). Briefly, previously conditioned samples were fitted onto Payne aluminium cups (diameter of $3.5 \mathrm{~cm}$ ) (Elcometer SPRL, Hermelle/s Argenteau, Belgium) containing $5 \mathrm{~mL}$ of deionised water and were placed in desiccators with saturated $\mathrm{Mg}\left(\mathrm{NO}_{3}\right)_{2}$ aqueous solution. A small fan was placed on top of each cup to favour the water vapour transport. The cups were weighed periodically with an analytical balance $( \pm$ $0.00001 \mathrm{~g}$ ), and weight loss vs. time was plotted to obtain the water vapour transmission rate (WVTR). Then, the WVP was calculated as described by Perdones et al. (2016). Measurements were carried out in triplicate.

The oxygen permeability (OP) of the conditioned samples was determined at $25{ }^{\circ} \mathrm{C}$ and $53 \% \mathrm{RH}$, following the guidance of the Standard Method D3985-05 (ASTM 2005). The equipment OXTRAN (Mocon Lippke, Neuwied, Germany) was used to determine the oxygen transmission rate (OTR). Film samples (area of $50 \mathrm{~cm}^{2}$ ) were exposed to pure oxygen flow on one side and pure nitrogen flow on the opposite side. The oxygen transmission values were registered every 10 min until equilibrium was reached. Then, the OP was determined as described by Cano et al. (2014), taking into account the samples' thickness. At least two replicates per formulation were considered.

\section{Mechanical Properties}

The tensile properties of the materials were assessed with a universal test machine (TA.XT plus model, Stable Micro Systems, Haslemere, England), following the guidelines of the ASTM standard method D882 (ASTM 2001), as previously described by Ortega-Toro et al. (2015). Conditioned samples $(25 \times 100 \mathrm{~mm})$ were fixed in the machine's extension grips (positioned $50 \mathrm{~mm}$ apart) and stretched at $50 \mathrm{~mm} \mathrm{~min}^{-1}$ until break. Tensile strength at break (TS), Young's modulus (YM), and elongation at break ( $\varepsilon \%)$ were obtained from the stress-strain curves. A minimum of eight measurements per sample were taken.

\section{Optical Properties}

The samples were analysed in terms of their transparency, by means of internal transmittance $\left(\mathrm{T}_{\mathrm{i}}\right)$ assessed by applying the Kubelka-Munk theory for multiple scattering (Hutchings 1999), as previously reported by Ortega-Toro et al. (2015). A spectrocolorimetre CM-3600d (Minolta Co., Tokyo, Japan) was used to determine the surface reflectance spectra (wavelength range 400-700 $\mathrm{nm}$ ) against black and white backgrounds. The value of $T_{i}$ at $460 \mathrm{~nm}$ was selected as the benchmark value for sample comparison.

\section{Thermogravimetric Analysis and Differential Scanning Calorimetry}

Previously, $\mathrm{P}_{2} \mathrm{O}_{5}$-conditioned films were submitted to thermal analyses. Their thermal degradation (thermogravimetric analysis (TGA)) was analysed with a thermogravimetric analyser (TGA/SDTA 851e, Mettler Toledo, Schwarzenbach, Switzerland). To this end, approximately $10 \mathrm{mg}$ of samples were placed into alumina crucibles (capacity $70 \mu \mathrm{L}$ ) and heated from 25 to $600{ }^{\circ} \mathrm{C}$ at a rate of $10 \mathrm{~K} / \mathrm{min}$, under nitrogen flow $(20 \mathrm{~mL} / \mathrm{min})$. The thermal weight loss curves (TA) and their derivatives (DTA) were obtained, and the onset, peak, and endset temperatures for each degradation peak were extracted by using the STARe Evaluation Software (Mettler Toledo, Inc., Switzerland). For the differential scanning calorimetry (DSC) analyses, a triple-step thermal scan was applied using the DSC equipment (1 StarE System, Mettler Toledo, Inc., Switzerland). Samples were cooled and kept at $-25^{\circ} \mathrm{C}$ for $5 \mathrm{~min}$ and then heated at $10 \mathrm{~K} / \mathrm{min}$ from -25 to $200{ }^{\circ} \mathrm{C}$, where they were maintained for $2 \mathrm{~min}$. Then, samples were cooled from 200 to $-25{ }^{\circ} \mathrm{C}$ at $10 \mathrm{~K} / \mathrm{min}$, maintained at -25 ${ }^{\circ} \mathrm{C}$ for $5 \mathrm{~min}$, and afterwards heated from -25 to $250^{\circ} \mathrm{C}$ at 10 $\mathrm{K} / \mathrm{min}$. As reference, an empty aluminium pan was used. All thermal analyses were done in duplicate.

\section{Statistical Analysis}

The analysis of the data was performed through variance analysis (ANOVA) using the Statgraphics Centurion XVII.64 software (Statgraphics Technologies, Inc., Warrenton, VA, USA). The Fisher least significant difference (LSD) was used to evaluate the differences $(p<0.05)$ among the samples' means.

\section{Results and Discussion}

\section{Changes in the PLA Surface Induced by Aminolisation}

The aminolisation process of the PLA surface was followed through the changes in the surface energy (SE) of the films 
(polar and dispersive components) and microstructural observations of the film surface by using FESEM. Contact angles of the different solvents on the PLA surface were constant with time for all pure solvents, except for ethyl acetate where changes occurred mainly due to the solvent volatility. Thus, only the contact angle value for 0 -s contact time was considered. From the contact angle measurements, and taking into account the values of the dispersive and polar components of the surface tension for the different pure solvents, the values of dispersive and polar components of the surface energy of PLA films were obtained. To this end, the linear fitting of Eq. 2, according to the variable combinations shown in the equation, was carried out. These obtained values are shown in Table 1 for the surfaces aminolised for different times. The total surface energy (sum of both components) was also determined at each aminolisation time. A notable increase (of almost 100\%) in the polar component value was observed at the shortest treatment times ( 1 and $3 \mathrm{~min}$ ). The film submitted to the 5min treatment did not show a similar trend, having values of the SE components that were more similar to the untreated sample. The changes (\% relative to the initial value) in mass and thickness of the treated samples are also shown in Table 1. Both parameters increased with treatment time, probably due to solvent adsorption and retention in the polymer matrix and its subsequent swelling. In fact, samples immersed only in solvent at the same temperature also gained mass, but in a lower proportion, as shown in Table 1 (values in brackets). In control treatments using only the solvent, the mass gain was greater than that in the reactive samples for all treatment times and reached a constant value of about $8 \%$ from 5 -min immersion onwards. This indicates that in the presence of reactive, mass change also involves other mechanisms related with the reaction, which could imply losses through the polymer solubilisation in the reactant media. In fact, the sample treated for 30 min exhibited a net weight loss, while the film thickness greatly increased, thus revealing the effective mass loss of the highly swollen film due to its partial solubilisation in the solvent-reactive system. Then, a prolonged contact with the diamine leads to a high degree of erosion/dissolution of the polylactide. Additionally, beyond the 10-min mark, the postaminolisation samples were visibly brittle. So, they were considered physically unfit for use in the subsequent coating step, as they would provide little mechanical support for the bilayers.

The FESEM micrographs in Fig. 2 show the surface aspect of the PLA films, where the changes provoked by the aminolisation process at different times can be observed. The initial relatively rough surface of the untreated polylactide films shows a gradual smoothening at short aminolisation times (1 and $3 \mathrm{~min}$ ), as also observed by other authors (Drobota et al. 2013). This can be attributed to the solubilisation of the more emerging zones of the rough surface overlapping with the aminolisation of the surface chains, as revealed by the increase in the polar component of the film surface energy. However, a more irregular surface was observed at 5-min treatments, where the surface tension polar component decreased. This suggests that aminolised chains could prevalently solubilise during treatment, generating an irregular film surface. For the 10-min treatment, visible voids can be observed in the films, confirming the internal action of the 1,6hexane diamine reactive and partial solubilisation of the film material. The internal diffusion of the reactive and solvent into the films seems to produce a highly porous structure at 15 - and 30-min treatments, as revealed by the visible pores in the film microstructure and the great increase in the film thickness. At the end of the latter treatment, the intense erosion of the films' structure can be clearly observed in Fig. 2, where a high ratio of voids and pores can be seen on the film surface, while the films appeared highly deformed after drying. In fact, the measurements of contact angle were not possible in these distorted films. Film immersion in pure solvent did not provoke a great alteration in the film surface beyond the leaching of the most superficial chains that changed the surface aspect of the films compared with the initial samples (Fig. 2).

The obtained results indicate that aminolisation of PLA films must be carried out for short times ( 1 or $3 \mathrm{~min}$ ), where the polar component of the film surface tension increased. Longer treatment times provoked internal damage in the film structure associated with the internal diffusion of reactants and
Table 1 Surface energy (SE) and its polar and dispersive components of PLA films submitted to different aminolisation times. Relative change (\%) with respect to the initial value in mass $(\Delta \mathrm{m})$ and thickness $(\Delta \mathrm{e})$ provoked by the process is shown. In brackets, the values of mass gain of films immersed only in solvent

\begin{tabular}{llllll}
\hline Aminolisation time (min) & \multicolumn{2}{l}{ PLA surface free energy $(\mathrm{mN} / \mathrm{m})$} & \multirow{2}{*}{$\Delta \mathrm{m}(\%)$} & $\Delta \mathrm{e}(\%)$ \\
\cline { 2 - 5 } & $\mathrm{SE}$ & Polar component & Dispersive component & \\
\hline 0 & 29.3 & 8.8 & 20.5 & $\mathrm{n} / \mathrm{a}$ & $\mathrm{n} / \mathrm{a}$ \\
1 & 37.0 & 18.5 & 18.5 & $0.5 \pm 0.2(1.2)$ & 7.6 \\
3 & 37.4 & 17.6 & 19.8 & $0.7 \pm 0.2(5.9)$ & 8.8 \\
5 & 31.7 & 9.1 & 22.6 & $1.1 \pm 0.2(7.9)$ & 17.2 \\
10 & 32.3 & 13.5 & 18.8 & $3.2 \pm 0.6(8.4)$ & 21.2 \\
15 & $\mathrm{n} / \mathrm{a}$ & $\mathrm{n} / \mathrm{a}$ & $\mathrm{n} / \mathrm{a}$ & $4.2 \pm 1.2(7.1)$ & 35.6 \\
30 & $\mathrm{n} / \mathrm{a}$ & $\mathrm{n} / \mathrm{a}$ & $\mathrm{n} / \mathrm{a}$ & $-5.49(8.6)$ & 419.2 \\
\hline
\end{tabular}


Fig. 2 FESEM micrographs of the PLA film surface submitted to the aminolisation treatment (different times). Magnification of $\times 10,000$ and $\times 1000$

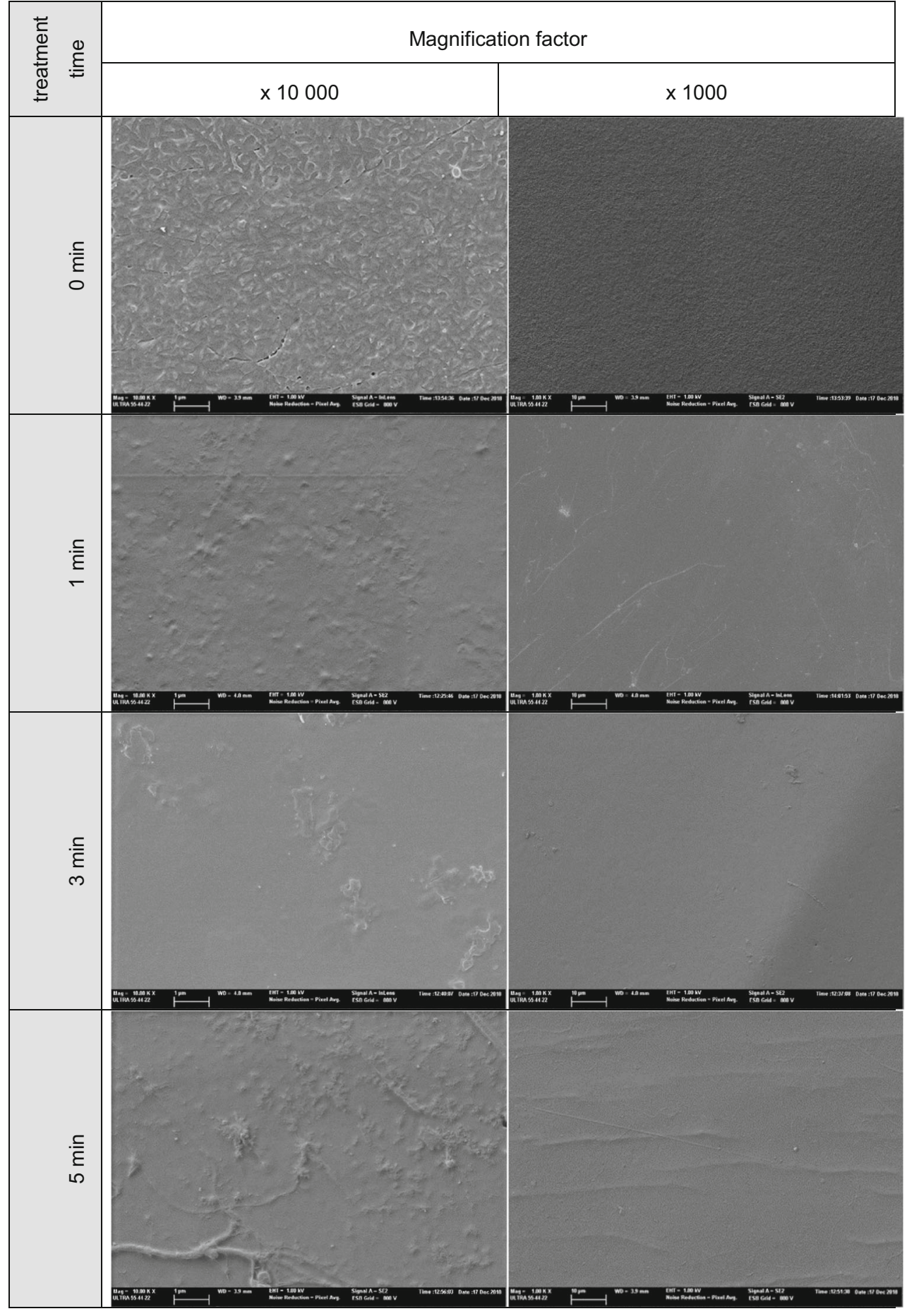

solvent that provoked the swelling of the polymer matrix and the partial solubilisation of the film components.

\section{Wettability of PLA with PVA Liquid Systems}

PLA films treated at 0-, 1-, and 3-min aminolisation (when the polar component of surface energy increased) were submitted to the wettability test with the PVA solutions/emulsions prepared as described in the "Mono- and Bilayer Preparation" section, containing or not carvacrol and different ratios of surfactant. Contact angles obtained between PVA liquid systems and the PLA films treated for different times are shown in Table 2, as well as the values of surface tension of the different PVA liquid systems. All contact angles were below $90^{\circ}$, indicating that the surface can be wetted by the liquids. The surface tension $\left(\gamma_{\mathrm{L}}\right)$ of the PVA liquid systems 


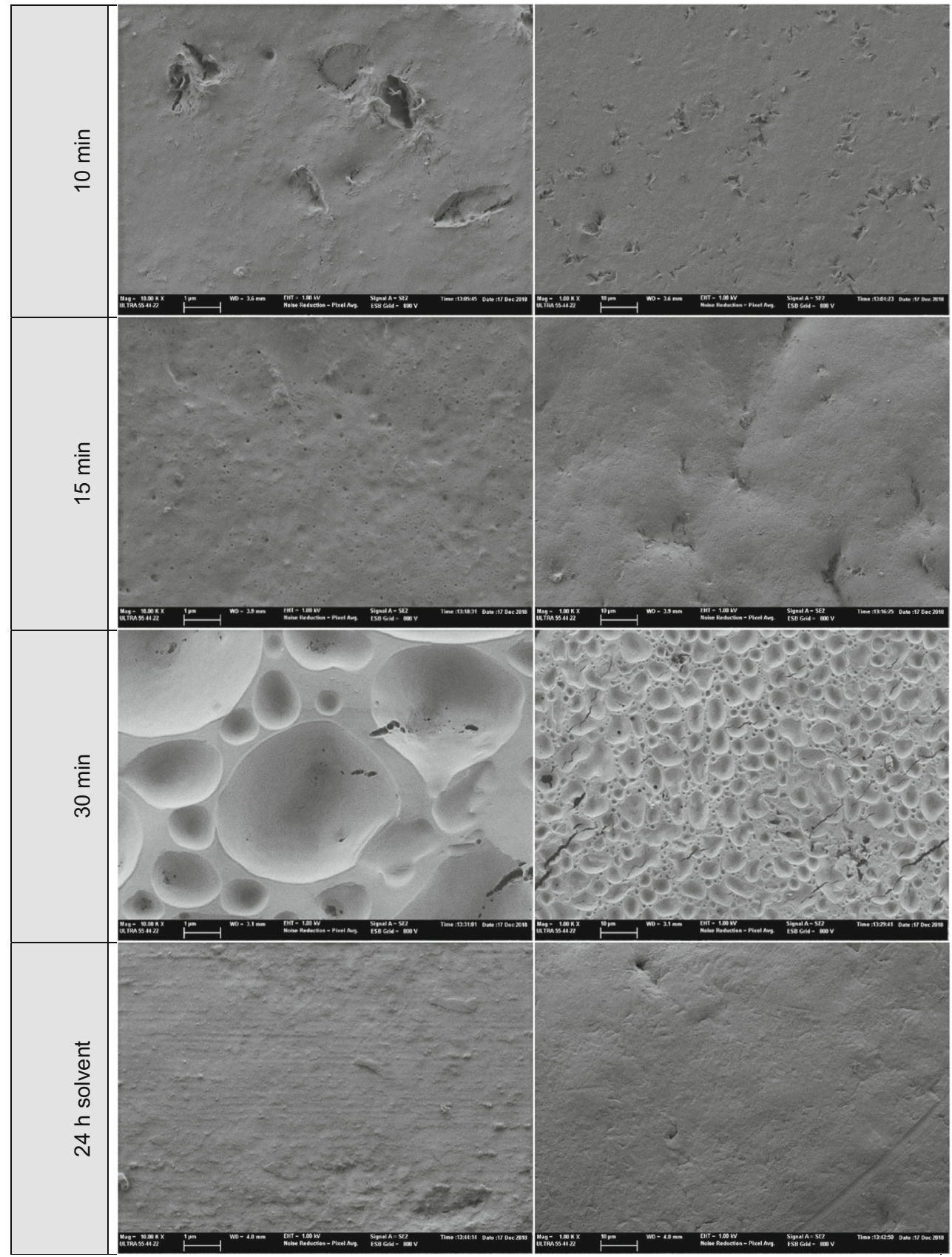

Fig. 2 (continued)

was significantly reduced by carvacrol incorporation, whereas no significant effect of the surfactant was observed at any ratio. The effect of the emulsified carvacrol on the surface tension of PVA solution can be attributed to the presence of small droplets of the compound at the liquid surface that modify the interfacial interaction forces due to its more hydrophobic nature. Likewise, the lack of a significant surfactant effect on the surface tension of the carvacrol emulsions could be due to its prevalent location at the oil-water interface and the main effect of carvacrol droplets at the surface level. This behaviour was also observed by Sapper et al. (2019) when thyme essential oil was emulsified in an aqueous solution of cassava starch-gellan with and without surfactant.

Concerning the contact angle, it decreased (from 51 to 33) for pure PVA solutions as the polar component of surface tension increased during aminolisation, thus reflecting the greater chemical affinity between the aminolised PLA surface and PVA aqueous solutions. However, for the PVA solution with emulsified carvacrol, the contact angle of non-aminolised PLA was lower (44) and less sensitive to the aminolisation time. This agrees with the greater surface affinity of the carvacrol-containing liquid with the initial PLA surface. In 
Table 2 Surface tension $\left(\gamma_{\mathrm{L}}\right)$ of the PVA solutions $(\mathrm{C} / \mathrm{S}$ wt. ratios are specified) and contact angles $(\theta)$ on PLA layer as a function of the aminolisation time. Different superscript letters $\left({ }^{\mathrm{a}, \mathrm{b}, \mathrm{c}}\right)$ and numbers $(1,2,3)$ in the same column and row, respectively, indicate significant $(p<0.05)$ differences between samples for the analysed parameter

\begin{tabular}{|c|c|c|c|c|c|}
\hline$\gamma_{\mathrm{L}}(\mathrm{mN} / \mathrm{m})$ & $\begin{array}{l}\text { PVA } \\
45.4 \pm 0.5^{2}\end{array}$ & $\begin{array}{l}\mathrm{PVA} / \mathrm{C} \\
36.0 \pm 0.3^{1}\end{array}$ & $\begin{array}{l}\mathrm{PVA}-\mathrm{C} / \mathrm{S} \\
(0.3: 100) \\
36.1 \pm 0.4^{1}\end{array}$ & $\begin{array}{l}\text { PVA-C/S } \\
(0.4: 100) \\
36.0 \pm 0.2^{1}\end{array}$ & $\begin{array}{l}\text { PVA-C/S } \\
(0.5: 100) \\
36.5 \pm 0.2^{1}\end{array}$ \\
\hline $\begin{array}{l}\text { Aminolisation time } \\
(\min )\end{array}$ & \multicolumn{5}{|c|}{ Contact angles $(\theta)$} \\
\hline 0 & $51 \pm 1^{\mathrm{c}, 4}$ & $44 \pm 2^{\mathrm{a}, 23}$ & $38 \pm 2^{\mathrm{a}, 1}$ & $41 \pm 2^{\mathrm{a}, 2}$ & $44 \pm 3^{\mathrm{ab}, 3}$ \\
\hline 1 & $44 \pm 3^{\mathrm{b}, 1}$ & $42 \pm 1^{\mathrm{a}, 1}$ & $45 \pm 7^{\mathrm{b}, 1}$ & $44 \pm 7^{\mathrm{ab}, 1}$ & $46 \pm 5^{\mathrm{bc}, 1}$ \\
\hline \multirow[t]{2}{*}{3} & $33 \pm 3^{\mathrm{a}, 1}$ & $47 \pm 6^{\mathrm{a}, 3}$ & $49 \pm 3^{b, 3}$ & $48 \pm 4^{\mathrm{b}, 3}$ & $42 \pm 3^{\mathrm{a}, 2}$ \\
\hline & \multicolumn{5}{|c|}{ Wettability parameter $\left(\mathrm{W}_{\mathrm{s}}\right)$} \\
\hline 0 & $\begin{array}{r}-17.0 \pm \\
1.0^{\mathrm{a} 1}\end{array}$ & $\begin{array}{r}-10.0 \pm \\
1.0^{\mathrm{a} 23}\end{array}$ & $-7.5 \pm 1.0^{\mathrm{b} 4}$ & $-9.0 \pm 0.7^{\mathrm{b} 3}$ & $-10.5 \pm 1.0^{\mathrm{ab} 2}$ \\
\hline 1 & $\begin{array}{r}-13.0 \pm \\
2.0^{\mathrm{b} 1}\end{array}$ & $\begin{array}{r}-9.5 \pm \\
1.0^{\mathrm{a} 2}\end{array}$ & $-11.0 \pm 3.0^{\mathrm{a} 12}$ & $-11.0 \pm 3.0^{\mathrm{ab} 12}$ & $-11.0 \pm 2.2^{\mathrm{a} 12}$ \\
\hline 3 & $\begin{array}{r}-7.0 \pm \\
2.0^{\mathrm{c} 3}\end{array}$ & $\begin{array}{c}-12.0 \pm \\
3.0^{\mathrm{a} 1}\end{array}$ & $-12.0 \pm 1.3^{\mathrm{a} 1}$ & $-12.0 \pm 2.0^{\mathrm{a} 1}$ & $-9.4 \pm 1.2^{\mathrm{b} 2}$ \\
\hline
\end{tabular}

fact, the contact angle of this emulsion increased in the case of the 3-min aminolisation treatment. The presence of surfactant provoked small changes in the contact angle, which could be attributed to specific interactions of the amphiphilic molecule with the PLA surface that affect the global surface forces at the solid-liquid-air contact. The small ratio of surfactant was more effective at decreasing the contact angle in non-aminolised PLA surfaces than the higher proportions, whereas it was not effective at reducing the contact angle in aminolised PLA surfaces.

The wettability parameter $\left(W_{\mathrm{s}}\right)$ values calculated for the different PVA formulations and PLA surfaces are also shown in Table 2 . The further from zero the values of $W_{\mathrm{s}}$ are, the less likely it is for that formulation to spread well over the PLA surface. Therefore, the best extensibility was obtained for the 3-min treated PLA films with pure PVA solutions, for the 1-min treated PLA films with PVA solution with emulsified carvacrol, and for the 0-min treated PLA support when emulsions contained the lowest ratio of surfactant. Therefore, the 1-min aminolised PLA support could be a compromise point to achieve a good extensibility of the different PVA liquid systems, while the lowest ratio of surfactant was more adequate to enhance the liquidphase extension. This choice implies an improvement in the extensibility of the pure PVA solution on PLA films, while a similar extensibility of the three PVA formulations (without and with carvacrol, containing or not surfactant) would be achieved. Thus, from this study, the aminolisation time selected for the subsequent application was $1 \mathrm{~min}$, and the PLA films treated for $1 \mathrm{~min}$ were coated with PVA, PVA/C, and PVA/C-S (0.3:100) formulations to obtain bilayer films whose functional properties were characterised.

\section{Functional Properties of PLA-PVA Bilayer Films}

The obtained bilayer films exhibited a thickness of 230-250 $\mu \mathrm{m}$, from which approximately $22 \%$ corresponded to the
PVA layer (56 $\pm 21-\mu \mathrm{m}$ average value) and the rest to the PLA sheet (195 $\pm 11-\mu \mathrm{m}$ average value). These values are coherent with the mass ratio of each polymer in the laminate (approximately 0.27 for PVA). However, at a microscopic level, a higher heterogeneity in the PVA thickness was detected, depending on the film sample. Figure 3 shows FESEM micrographs of some bilayer films, where differences in the overall thickness of the PVA sheet can be seen, as well as differences in the thickness along a determined film, depending on the roughness of the PLA surface.

When a small protuberance appeared in the PLA surface (dotted arrows, Fig. 3), the PVA layer was thinner, which can be critical when the coating was very thin. This aspect could compromise the barrier capacity provided by the PVA layer in the zones where its thickness was extremely thin (about $10 \mu \mathrm{m}$ ). Then, in the laminates obtained by casting PVA solutions on PLA surface, the more hydrophobic PLA layer was thicker, whereas the cast hydrophilic layer of PVA was thinner with great variability in thickness, which could influence its effectiveness at controlling its barrier capacity (Debeaufort et al. 1993).

Given that most deteriorative processes in foods are caused by water or oxygen exchanges, food packaging materials require a good barrier capacity against moisture and oxygen to extend foodstuff shelf life (Cerqueira et al. 2009). The WVP and OP of the obtained bilayers are shown in Table 3, together with the corresponding values of each monolayer. According to the ideal laminate theory (Siracusa 2012), the polymer layer with lower permeability usually determines the barrier capacity of laminates for water vapour or gases. As such, the WVP values of bilayers were expected to be around those of the PLA sheet that exhibited the lowest WVP. Indeed, the WVP of bilayers presents similar values to those of the PLA monolayer with small differences between the different samples. Laminates with aminolised PLA exhibited a wider WVP range, the bilayer with the pure PVA sheet being the one with the lowest value. 
Fig. 3 Micrographs of several bilayer cross-sections. Top row, aminolised PLA with PVA (left) and PVA/C/S (right) coatings. Bottom row, untreated PLA with PVA/C (left) and PVA/C/S (right) coatings. Dotted arrows indicate protuberances at PLA surface

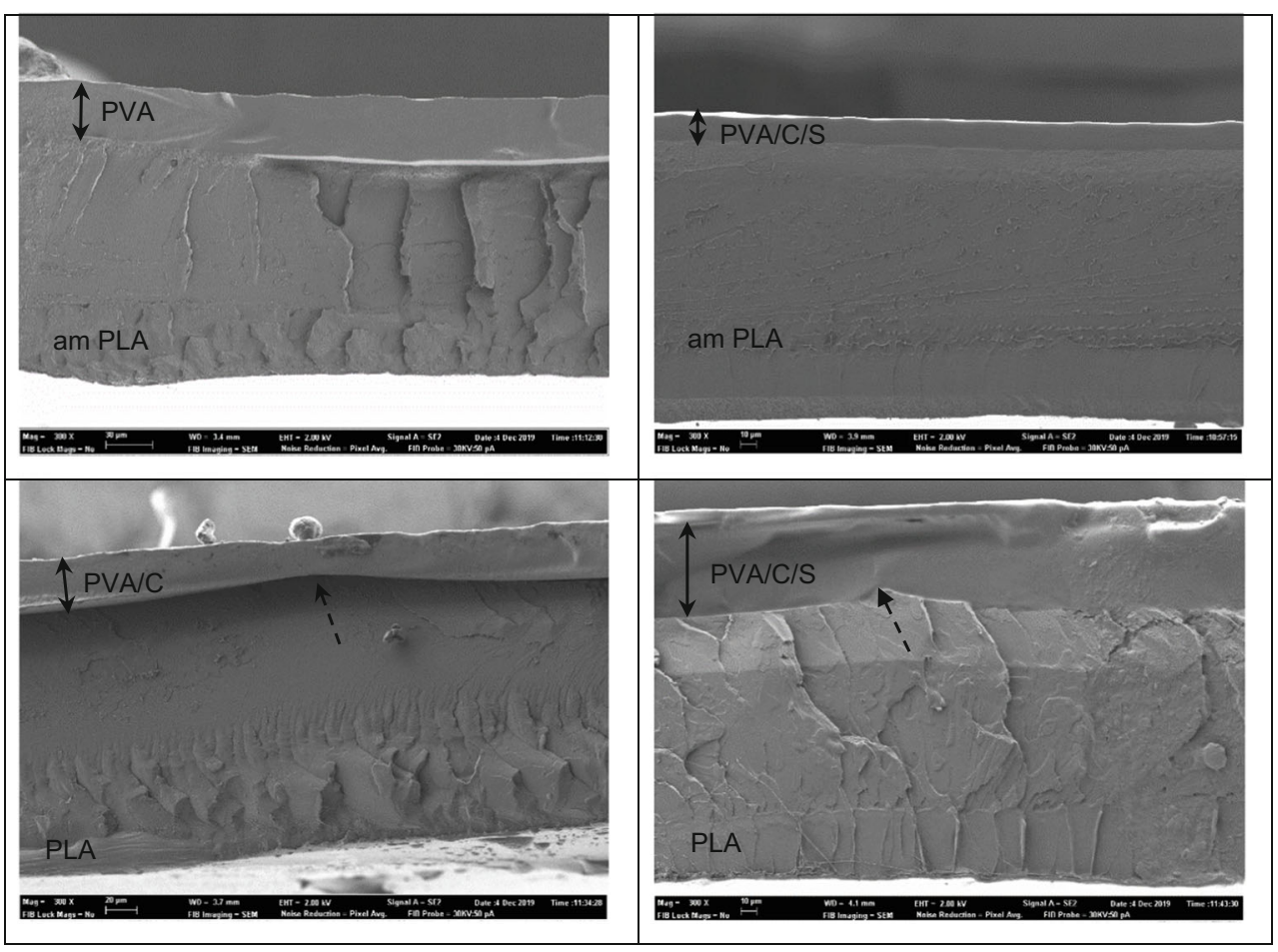

However, the values of oxygen permeability were not in the range of that of the PVA sheet that should be the limiting layer for oxygen transmission. Both the aminolised bilayers and those non-aminolised with pure PVA showed similar OP values to those of the PLA monolayer. In contrast, nonaminolised laminates containing carvacrol (with and without surfactant) exhibited lower OP values. This could be attributed to the oxygen-blocking effect exerted by the antioxidant CA, but this was not observed in bilayers with aminolised PLA. The lack of effectiveness of PVA sheets in reducing the OP of laminates could be due to the heterogeneous coating at microscopic level that should generate regions in the films with very thin hydrophilic coating. Thus, oxygen transfer would take place, mainly limited by the PLA sheet.

The tensile properties (Young's modulus (YM), tensile strength (TS), and elongation ( $\varepsilon$ ) at break) of bilayers are also presented in Table 3. The bilayers exhibited tensile property values in the range of the stiffest PLA sheet, which also represents the thickest layer of the assembly. The films containing CA with and without surfactant had the lowest values of YM, regardless of the aminolisation of the PLA sheet. This could be explained by the partial carvacrol migration into the PLA sheet, weakening the inter-chain forces of the PLA matrix. This effect was also appreciated in the values of the bilayer's resistance to break (TS), which were higher when neither CA nor T85 was present, showing values similar to those of the PLA monolayer. All materials had elongation at break values of under $10 \%$, denoting a quite brittle behaviour, in the order of PLA films. However, a slight increase in the film extensibility could be appreciated for the CA-carrying laminates, in line with the plasticising effect of the CA that potentially migrated into the PLA sheets.

The internal transmittance $\left(\mathrm{T}_{\mathrm{i}}\right)$, also presented in Table 3 , is directly related to the film transparency. All of the aminolised sheets presented a cloudiness (photos not shown) as a result of the aminolisation step. This explains the decrease in the $T_{i}$ parameter for these treated materials. However, this acquired opacity could be considered positive for certain food packaging applications, where a reduction in light-induced oxidative reactions is required.

The results indicate that bilayer PLA-PVA films obtained by casting PVA aqueous solutions onto the PLA surface did not provide additional benefits to the PLA monolayers. The expected barrier capacity against oxygen potentially imparted by the PVA sheet was not effective, while the PVA did not contribute to the mechanical reinforcement of the PLA layer. Despite PLA aminolisation enhancing the polar nature of the PLA surface and thus the chemical affinity with the PVA aqueous solutions to be extended, the obtained PVA coatings were heterogeneous in thickness, and the thinner regions seem to limit the barrier capacity of the coating against oxygen.

\section{Thermal Behaviour as Affected by the Aminolisation Treatment}

A thermal analysis of the obtained materials was carried out in order to discover the effect of aminolisation and lamination on the physical state of polymers, which, in turn, affects their functional properties. Table 4 summarises the degradation temperatures of the different samples, as obtained by using 
Table 3 Barrier and mechanical properties of bilayer PVA-PLA films. Film thickness and transparency $\left(\mathrm{T}_{\mathrm{i}}\right)$ are also shown. Different superscript letters in the same column indicate significant differences $(p<0.05)$ between samples

\begin{tabular}{|c|c|c|c|c|c|c|}
\hline $\begin{array}{l}\text { WVP x } 10^{10} \\
(\mathrm{~g} / \mathrm{Pa} \mathrm{s})\end{array}$ & $\begin{array}{l}\mathrm{OP} \times 10^{12} \\
\left(\mathrm{~cm}^{3} / \mathrm{m} \mathrm{s} \mathrm{Pa}\right)\end{array}$ & $\begin{array}{l}\text { Young's modulus } \\
(\mathrm{MPa})\end{array}$ & $\begin{array}{l}\text { Tensile strength } \\
(\mathrm{MPa})\end{array}$ & $\varepsilon(\%)$ & $\begin{array}{l}\text { Thickness } \\
(\mathrm{mm})\end{array}$ & $\mathrm{T}_{\mathrm{i}}$ at $460 \mathrm{~nm}(\%)$ \\
\hline
\end{tabular}

Multilayer components

\begin{tabular}{|c|c|c|c|c|c|c|c|c|}
\hline \multirow[t]{3}{*}{ am-PLA } & PVA & $0.28 \pm 0.03^{\mathrm{a}}$ & $4.45 \pm 0.47^{b}$ & $1300 \pm 200^{\mathrm{bc}}$ & $53 \pm 8^{\mathrm{b}}$ & $4.9 \pm 0.5^{\mathrm{a}}$ & $0.251 \pm 0.060^{\mathrm{a}}$ & $56 \pm 13^{\mathrm{a}}$ \\
\hline & PVA-C & $0.36 \pm 0.05^{\mathrm{ab}}$ & $5.02 \pm 0.32^{\mathrm{bc}}$ & $1140 \pm 150^{\mathrm{ab}}$ & $40 \pm 7^{\mathrm{a}}$ & $5.4 \pm 0.4^{\mathrm{ab}}$ & $0.231 \pm 0.019^{\mathrm{a}}$ & $69 \pm 10^{\mathrm{b}}$ \\
\hline & $\mathrm{PVA}-\mathrm{C} / \mathrm{S}$ & $0.40 \pm 0.09^{\mathrm{b}}$ & $5.89 \pm 1.07^{\mathrm{c}}$ & $1100 \pm 300^{\mathrm{a}}$ & $41 \pm 5^{\mathrm{a}}$ & $6.7 \pm 2.5^{\mathrm{bc}}$ & $0.236 \pm 0.013^{\mathrm{a}}$ & $60 \pm 5^{\mathrm{a}}$ \\
\hline \multirow[t]{3}{*}{ PLA } & PVA & $0.37 \pm 0.05^{\mathrm{ab}}$ & $4.07 \pm 0.16^{\mathrm{b}}$ & $1400 \pm 50^{\mathrm{c}}$ & $49 \pm 3^{b}$ & $5.8 \pm 0.9^{\mathrm{ab}}$ & $0.230 \pm 0.018^{\mathrm{a}}$ & $86.2 \pm 0.3^{\mathrm{c}}$ \\
\hline & PVA-C & $0.33 \pm 0.01^{\mathrm{ab}}$ & $0.15 \pm 0.02^{\mathrm{a}}$ & $1100 \pm 120^{\mathrm{ab}}$ & $42 \pm 5^{\mathrm{a}}$ & $7.9 \pm 2.1^{\mathrm{cd}}$ & $0.247 \pm 0.022^{\mathrm{a}}$ & $86 \pm 1^{\mathrm{c}}$ \\
\hline & $\mathrm{PVA}-\mathrm{C} / \mathrm{S}$ & $0.36 \pm 0.02^{\mathrm{ab}}$ & $0.20 \pm 0.06^{\mathrm{a}}$ & $1150 \pm 110^{\mathrm{ab}}$ & $41 \pm 4^{\mathrm{a}}$ & $8.9 \pm 1.0^{\mathrm{d}}$ & $0.240 \pm 0.010^{\mathrm{a}}$ & $85 \pm 4^{\mathrm{c}}$ \\
\hline \multicolumn{9}{|c|}{ Monolayers } \\
\hline & PVA & $8.05 \pm 0.06$ & $0.0015 \pm 0.02$ & $54 \pm 5$ & $46 \pm 6$ & $97 \pm 6$ & $0.065 \pm 0.002$ & $86 \pm 1$ \\
\hline & PLA & $0.44 \pm 0.03$ & $4.66 \pm 0.03$ & $1370 \pm 34$ & $53 \pm 2$ & $4.3 \pm 0.2$ & $0.22 \pm 0.01$ & $87.7 \pm 0.2$ \\
\hline
\end{tabular}

the thermogravimetric analysis. TGA thermographs (Fig. 4) show an overlapping of the degradation steps of both polymers due to the proximity of its degradation temperature range. The aminolisation process did not modify the degradation temperature of PLA, the peak being at $310^{\circ} \mathrm{C}$. PVA starts its degradation and exhibits the peak at a lower temperature $\left(192 / 288^{\circ} \mathrm{C}\right)$ than the PLA. Thus, bilayers showed notable

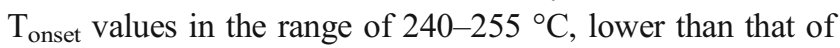
pure PLA $\left(269^{\circ} \mathrm{C}\right)$. A second and third small degradation peaks appeared in bilayers at about 390 and $500{ }^{\circ} \mathrm{C}$, which could be attributed to the PVA degradation in subsequent steps as described by other authors (Bonilla et al. 2014; Cano et al. 2016). No significant differences were observed between the degradation behaviour of the different bilayers. No thermo-release of carvacrol from the corresponding bilayers was detected, probably due to the very small mass fraction of the compound in the laminate: about 11-g/g PVA, according to previous studies (Tampau et al. 2020). Table 4 also shows the glass transition temperature $\left(\mathrm{T}_{\mathrm{g}}\right)$ for the different materials obtained in the first and second heating scans. In the first heating step, two distinct $\mathrm{T}_{\mathrm{g}}$ can be observed, corresponding to the two polymers present in bilayers. For samples without carvacrol, the first one, at a slightly lower temperature, corresponds to the PLA, while the second one must be attributed to the PVA. For laminates without carvacrol, both transitions practically overlap, but these are more decoupled for bilayers with carvacrol due to the plasticising effect of the compound that shifts the transition of the PVA sheet to a lower temperature, below the $\mathrm{T}_{\mathrm{g}}$ of PLA. The DSC thermograms (Fig. 5) also revealed the typical relaxation of PLA after $T_{g}$ in the first heating step, associated with polymer ageing (Muller et al. 2016). However, as the thermal history of the

Table 4 Thermal parameters of polymers in the multilayer assemblies. Values of pure, non-treated polymers are also included. Different superscript letters in the same column indicate significant differences $(p<0.05)$ between specimens

\begin{tabular}{|c|c|c|c|c|c|c|c|c|c|c|}
\hline \multicolumn{2}{|c|}{ Bilayer/monolayer } & \multicolumn{4}{|l|}{ TGA* } & \multicolumn{5}{|l|}{ DSC } \\
\hline & & & & & & \multicolumn{4}{|l|}{ 1st heating } & \multirow{2}{*}{$\begin{array}{l}\text { 2nd heating } \\
\mathrm{T}_{\mathrm{g}}\left({ }^{\circ} \mathrm{C}\right)\end{array}$} \\
\hline & & $\mathrm{T}_{\text {onset } 1}\left({ }^{\circ} \mathrm{C}\right)$ & $\mathrm{T}_{\text {peak } 1}\left({ }^{\circ} \mathrm{C}\right)$ & $\mathrm{T}_{\text {peak } 2}\left({ }^{\circ} \mathrm{C}\right)$ & $\mathrm{T}_{\text {peak } 3}\left({ }^{\circ} \mathrm{C}\right)$ & $\mathrm{T}_{\mathrm{g} \text { PLA }}\left({ }^{\circ} \mathrm{C}\right)$ & $\mathrm{T}_{\mathrm{g} \text { PVA }}\left({ }^{\circ} \mathrm{C}\right)$ & $\mathrm{T}_{\text {peak }}\left({ }^{\circ} \mathrm{C}\right)$ & $\Delta \mathrm{H}(\mathrm{J} / \mathrm{g}$ PVA $)$ & \\
\hline \multirow[t]{3}{*}{ am-PLA } & PVA & $248 \pm 2^{\mathrm{cd}}$ & $286 \pm 3^{\mathrm{ab}}$ & $392 \pm 2^{\mathrm{ab}}$ & $511 \pm 27^{\mathrm{a}}$ & $56 \pm 1^{\mathrm{b}}$ & $68.4 \pm 1.0^{\mathrm{d}}$ & $185 \pm 1^{\mathrm{ab}}$ & $34 \pm 4^{\mathrm{a}}$ & $52 \pm 3^{c}$ \\
\hline & PVA-C & $244.9 \pm 0.3^{\mathrm{bcd}}$ & $286 \pm 1^{\mathrm{ab}}$ & $391 \pm 1^{\mathrm{a}}$ & $496 \pm 6^{\mathrm{a}}$ & $56.2 \pm 0.4^{\mathrm{b}}$ & $43.8 \pm 0.3^{\mathrm{a}}$ & $187 \pm 1^{\mathrm{b}}$ & $17 \pm 2^{\mathrm{a}}$ & $44 \pm 1^{\mathrm{a}}$ \\
\hline & $\mathrm{PVA}-\mathrm{C} / \mathrm{S}$ & $246 \pm 1^{\text {bcd }}$ & $289 \pm 1^{\mathrm{b}}$ & $393 \pm 0^{\mathrm{ab}}$ & $508 \pm 1^{\mathrm{a}}$ & $57.6 \pm 0.0^{\mathrm{c}}$ & $45.2 \pm 0.2^{\mathrm{b}}$ & $188 \pm 1^{b}$ & $33 \pm 28^{\mathrm{a}}$ & $49 \pm 2^{b c}$ \\
\hline \multirow[t]{3}{*}{ PLA } & PVA & $244 \pm 1^{\mathrm{bc}}$ & $280 \pm 1^{\mathrm{a}}$ & $398 \pm 2^{\mathrm{b}}$ & $508 \pm 2^{\mathrm{a}}$ & $56.0 \pm 1.0^{\mathrm{b}}$ & $68.9 \pm 0.1^{\mathrm{d}}$ & $189 \pm 2^{b}$ & $84 \pm 43^{b}$ & $53 \pm 2^{c}$ \\
\hline & PVA-C & $251 \pm 4^{\mathrm{d}}$ & $292 \pm 7^{b}$ & $396 \pm 1^{\mathrm{ab}}$ & $504 \pm 28^{\mathrm{a}}$ & $57.8 \pm 0.7^{\mathrm{c}}$ & $44.3 \pm 0.7^{\mathrm{ab}}$ & $183 \pm 1^{\mathrm{a}}$ & $25 \pm 7^{\mathrm{a}}$ & $47 \pm 2^{\mathrm{ab}}$ \\
\hline & $\mathrm{PVA}-\mathrm{C} / \mathrm{S}$ & $241 \pm 2^{\mathrm{b}}$ & $279 \pm 2^{\mathrm{a}}$ & $392 \pm 1^{\mathrm{ab}}$ & $530 \pm 12^{\mathrm{a}}$ & $58.2 \pm 0.0^{\mathrm{c}}$ & $44.6 \pm 0.3^{\mathrm{ab}}$ & $186 \pm 1^{\mathrm{ab}}$ & $23 \pm 8^{\mathrm{a}}$ & $45 \pm 1^{\mathrm{ab}}$ \\
\hline \multicolumn{2}{|l|}{ am-PLA } & $268 \pm 1^{\mathrm{e}}$ & $310 \pm 1^{\mathrm{c}}$ & - & - & $55 \pm 1^{\mathrm{ab}}$ & - & - & - & $51.9 \pm 0.1^{\mathrm{c}}$ \\
\hline \multicolumn{2}{|l|}{ PLA } & $269 \pm 5^{\mathrm{e}}$ & $310 \pm 4^{\mathrm{c}}$ & - & - & $54.4 \pm 0.2^{\mathrm{a}}$ & - & - & - & $53 \pm 2^{c}$ \\
\hline \multicolumn{2}{|l|}{ PVA } & $192 \pm 1^{\mathrm{a}}$ & $288 \pm 4^{\mathrm{b}}$ & $398 \pm 6^{\mathrm{b}}$ & - & - & $55.0 \pm 0.3^{\mathrm{c}}$ & - & $50 \pm 3^{\mathrm{ab}}$ & $63 \pm 3^{d}$ \\
\hline
\end{tabular}

*No residue was observed at $600{ }^{\circ} \mathrm{C}$ 


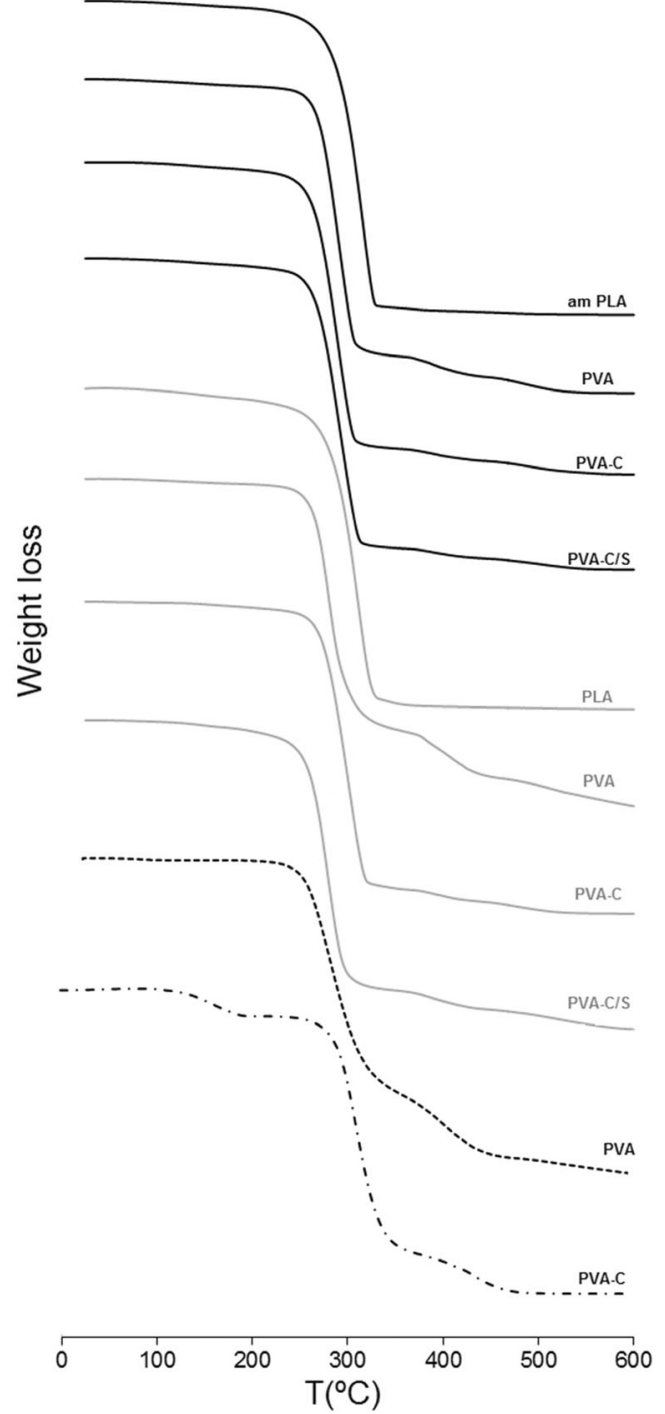

Fig. 4 TGA curves of multilayer assemblies with PLA, aminolised (black curves) or not (grey curves), and PVA, containing or not carvacrol (C) and surfactant (S).

materials is erased and they become melt blended in the first step, only a single $T_{g}$ was observed in the second heating, without relaxation enthalpy. This $\mathrm{T}_{\mathrm{g}}$ value was lower for laminates with carvacrol, thus indicating the plasticising effect of the compound on the melt-blended polymer matrix.

Likewise, PVA crystallises in the laminate, and the melting temperature and enthalpies are shown in Table 4. Polymer melting was observed from about $160^{\circ} \mathrm{C}$, with a peak at about $185^{\circ} \mathrm{C}$, in agreement with other studies (Tampau et al. 2020). However, a high degree of variability was observed in the melting enthalpy of PVA when expressed per $g$ of polymer, in both the first and the second (values not shown) heating steps, assuming a constant mass fraction of PVA in the bilayer film. Nevertheless, the variable thickness observed in the layers could imply notable differences in the PVA ratio in the DSC-analysed samples. This could explain the variability
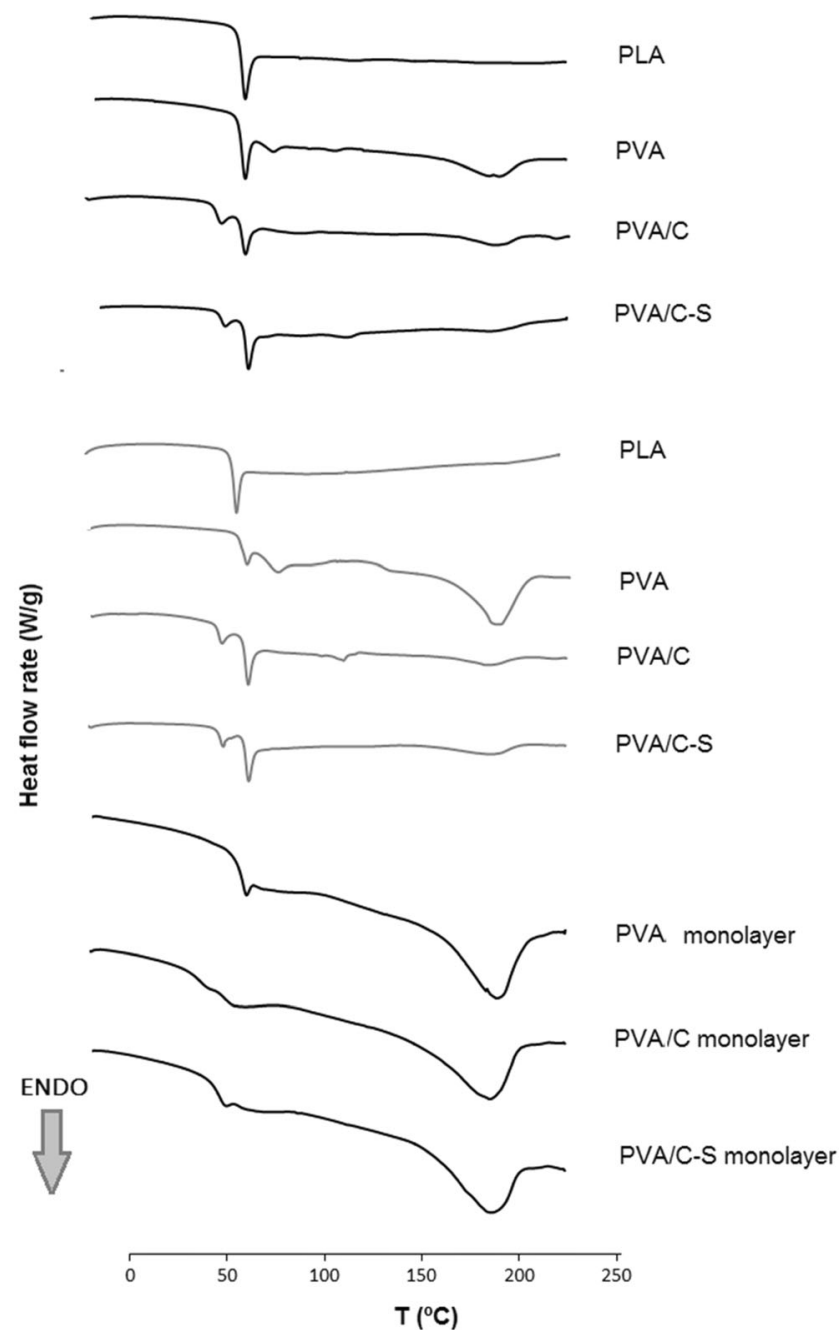

Fig. 5 DSC curves of multilayer assemblies with PLA, aminolised (black curves) or not (grey curves), and PVA, containing or not carvacrol (C) and surfactant (S). Monolayers of aminolised PLA (solid black curve), untreated PLA (solid grey curve), and PVA are also included

in the melting enthalpy and corroborate the heterogeneous coating in the bilayer obtained by casting.

Therefore, DSC analyses revealed the amorphous state of PLA and the semicrystalline nature of PVA in the laminates, without any appreciable effect of the PLA aminolisation. However, the variability in the PVA melting enthalpy points to the heterogeneity of the coating on the laminate obtained by casting, even in the case of aminolised PLA, where wettability was enhanced.

\section{Conclusions}

The aminolisation technique applied for less than 3 min yields PLA surfaces with a greater polar component of the surface free energy (100\% increase), thus enhancing wettability with polar solutions of PVA. The prolonged ( $>3 \mathrm{~min}$ ) exposure to 1,6-hexanediamine had negative effects on the polar 
component and microstructure of the PLA films. Extensibility of the liquid phase containing carvacrol on the PLA sheet was not improved by aminolisation. Mechanical and barrier properties of PLA-PVA bilayers containing, or not, carvacrol were not significantly affected by the aminolisation treatment and were very close to the properties of the major PLA monolayer. Therefore, the PVA sheet did not provide the expected oxygen barrier capacity to the laminate. Carvacrol promoted the bilayer stretchability due to its plasticising effect on both PVA and PLA sheets. Thus, coating PLA sheets (aminolised or not) with PVA solutions is not recommended for the purposes of obtaining laminates for food packaging applications, since neither the barrier nor the mechanical properties were an improvement on those of PLA films, mainly due to the heterogeneous thickness of the PVA coating.

Code Availability Not applicable.

Authors' Contributions A. Tampau: writing of original draft, reviewing, editing, data curation, and investigation methodology. C. GonzálezMartínez: supervision, writing, reviewing, and editing. A. A. Vicente: supervision, writing, reviewing, and editing. A. Chiralt: supervision, writing, reviewing, and editing.

Funding Information The authors acknowledge the financial support provided by the Ministerio de Economia y Competitividad (MINECO) of Spain (project AGL2016-76699-R). The author A. Tampau thanks MINECO for the pre-doctoral research grant \#BES-2014-068100.

Data Availability The raw/processed data required to reproduce these findings cannot be shared at this time due to legal or ethical reasons.

\section{Compliance with Ethical Standards}

Conflict of Interest The authors declare that they have no conflict of interest.

Ethics Approval Not applicable.

Consent to Participate Not applicable.

Consent for Publication Not applicable.

\section{References}

Anwar, R. W., Sugiarto, \& Warsiki, E. (2018). The comparison of antimicrobial packaging properties with different applications incorporation method of active material. IOP Conference Series: Earth and Environmental Science, 141(1), 012002.

ASTM. (2001). Standard test method for tensile properties of thin plastic sheeting. Standard D882. Annual book of American standard testing methods (pp. 162-170). Philadelphia: American Society for Testing and Materials.

ASTM. (2005). Standard test method for oxygen gas transmission rate through plastic film and sheeting using a coulometric sensor. Standard designations: 3985-05. Annual book of ASTM standards.
West Conshohocken, PA: American Society for Testing and Materials.

ASTM. (1995). Standard test methods for water vapor transmission of materials. Standard designations: E96-95. Annual book of ASTM standards (pp. 406-413). Philadelphia: American Society for Testing and Materials.

Bonilla, J., Fortunati, E., Vargas, M., Chiralt, A., \& Kenny, J. M. (2013). Effects of chitosan on the physicochemical and antimicrobial properties of PLA films. Journal of Food Engineering, 119(2), 236-243.

Bonilla, J., Fortunati, E., Atarés, L., Chiralt, A., \& Kenny, J. M. (2014). Physical, structural and antimicrobial properties of poly vinyl alcohol-chitosan biodegradable films. Food Hydrocolloids, 35, 463-470.

Burt, S. (2004). Essential oils: their antibacterial properties and potential applications in foods-a review. International Journal of Food Microbiology, 94(3), 223-253.

Can Baser, K. (2008). Biological and pharmacological activities of carvacrol and carvacrol bearing essential oils. Current Pharmaceutical Design, 14(29), 3106-3119.

Cano, A., Jiménez, A., Cháfer, M., Gónzalez, C., \& Chiralt, A. (2014). Effect of amylose:amylopectin ratio and rice bran addition on starch films properties. Carbohydrate Polymers, 111, 543-555.

Cano, A., Fortunati, E., Cháfer, M., Kenny, J. M., Chiralt, A., \& González-Martínez, C. (2015). Properties and ageing behaviour of pea starch films as affected by blend with poly(vinyl alcohol). Food Hydrocolloids, 48, 84-93.

Cano, A. I., Cháfer, M., Chiralt, A., \& González-Martínez, C. (2016). Biodegradation behaviour of starch-PVA films as affected by the incorporation of different antimicrobials. Polymer Degradation and Stability, 132, 11-20.

Carneiro-da-Cunha, M. G., Cerqueira, M. A., Souza, B. W. S., Souza, M. P., Teixeira, J. A., \& Vicente, A. A. (2009). Physical properties of edible coatings and films made with a polysaccharide from Anacardium occidentale L. Journal of Food Engineering, 95(3), 379-385.

Carneiro-da-Cunha, M. G., Cerqueira, M. A., Souza, B. W. S., Carvalho, S., Quintas, M. A. C., Teixeira, J. A., \& Vicente, A. A. (2010). Physical and thermal properties of a chitosan/alginate nanolayered PET film. Carbohydrate Polymers, 82(1), 153-159.

Cerqueira, M. A., Lima, Á. M., Teixeira, J. A., Moreira, R. A., \& Vicente, A. A. (2009). Suitability of novel galactomannans as edible coatings for tropical fruits. Journal of Food Engineering, 94(3-4), 372-378.

Collazo-Bigliardi, S., Ortega-Toro, R., \& Chiralt, A. (2018). Properties of micro- and nano-reinforced biopolymers for food applications. Polymers for Food Applications (T. J. Gutiérrez, ed.).

Debeaufort, F., Martin-Polo, M., \& Voilley, A. (1993). Polarity homogeneity and structure affect water vapor permeability of model edible films. Journal of Food Science, 58(2), 426-429.

DeMerlis, C. C., \& Schoneker, D. R. (2003). Review of the oral toxicity of polyvinyl alcohol (PVA). Food and Chemical Toxicology, 41(3), 319-326.

Drobota, M., Persin, Z., Zemljic, L., Mohan, T., Stana-Kleinschek, K., Doliska, A., \& Coseri, S. (2013). Chemical modification and characterization of poly(ethylene terephthalate) surfaces for collagen immobilization. Open Chemistry, 11(11).

Fabra, M. J., Flores-López, M. L., Cerqueira, M. A., de Rodriguez, D. J., Lagaron, J. M., \& Vicente, A. A. (2016). Layer-by-layer technique to developing functional nanolaminate films with antifungal activity. Food and Bioprocess Technology, 9(3), 471-480.

Farrington, D. W., Lunt, J., Davies, S., \& Blackburn, R. S. (2005). 6Poly(lactic acid) fibers. In R. S. B. T.-B. and S. F. Blackburn (Ed.), Woodhead Publishing Series in Textiles (pp. 191-220).

Gennadios, A., Weller, C. L., \& Gooding, C. H. (1994). Measurement errors in water vapour permeability of highly permeable, hydrophilic edible films. Journal of Food Engineering, 21(4), 395-409. 
Hejda, F., Solař, P., \& Kousal, J. (2010). Surface free energy determination by contact angle measurements-a comparison of various approaches. (3), 25-30. Retrieved online from: https://pdfs.semanticscholar.org/e5a0/ e7dc916cfeb7f0b4a3e24027cf7421d5d5e0.pdf (September 2019).

Hsu J. C.-H., \& Guckenberger, A. C. (1985). EP0175451A2. Retrieved from https://patents.google.com/patent/EP0175451A2/ru (September 2019)

Hutchings, J. B. (1999). Food and colour appearance. Chapman and Hall food science book (2nd ed.). Gaithersburg: Aspen Publication.

Kamimura, J. A., Santos, E. H., Hill, L. E., \& Gomes, C. L. (2014). Antimicrobial and antioxidant activities of carvacrol microencapsulated in hydroxypropyl-beta-cyclodextrin. LWT - Food Science and Technology, 57(2), 701-709.

Kwok, D. Y., \& Neumann, A. W. (1999). Contact angle measurement and contact angle interpretation. In Advances in Colloid and Interface Science, 81(3), 167-249.

Mascheroni, E., Guillard, V., Gastaldi, E., Gontard, N., \& Chalier, P. (2011). Anti-microbial effectiveness of relative humiditycontrolled carvacrol release from wheat gluten/montmorillonite coated papers. Food Control, 22(10), 1582-1591.

Medeiros, B. G. D. S., Pinheiro, A. C., Teixeira, J. A., Vicente, A. A., \& Carneiro-da-Cunha, M. G. (2012). Polysaccharide/protein nanomultilayer coatings: construction, characterization and evaluation of their effect on "Rocha" pear (Pyrus communis L.) Shelf-Life. Food and Bioprocess Technology, 5(6), 2435-2445.

Medeiros, B. G. D. S., Souza, M. P., Pinheiro, A. C., Bourbon, A. I., Cerqueira, M. A., Vicente, A. A., \& Carneiro-da-Cunha, M. G. (2014). Physical characterisation of an alginate/lysozyme nanolaminate coating and its evaluation on "Coalho" cheese shelf life. Food and Bioprocess Technology, 7(4), 1088-1098.

Muller, J., Jiménez, A., González-Martínez, C., \& Chiralt, A. (2016). Influence of plasticizers on thermal properties and crystallization behaviour of poly(lactic acid) films obtained by compression moulding. Polymer International, 65(8), 970-978.

Muller, J., González-Martínez, C., \& Chiralt, A. (2017a). Poly(lactic) acid (PLA) and starch bilayer films, containing cinnamaldehyde, obtained by compression moulding. European Polymer Journal, 95(July), 56-70.

Muller, J., Casado Quesada, A., González-Martínez, C., \& Chiralt, A. (2017b). Antimicrobial properties and release of cinnamaldehyde in bilayer films based on polylactic acid (PLA) and starch. European Polymer Journal, 96(May), 316-325.

Noel, S., Liberelle, B., Yogi, A., Moreno, M. J., Bureau, M. N., Robitaille, L., \& De Crescenzo, G. (2013). A non-damaging chemical amination protocol for poly(ethylene terephthalate)-application to the design of functionalized compliant vascular grafts. J. Mater. Chem. B, 1(2), 230-238.

Ortega-Toro, R., Contreras, J., Talens, P., \& Chiralt, A. (2015). Physical and structural properties and thermal behaviour of starch-poly $(\varepsilon-$ caprolactone) blend films for food packaging. Food Packaging and Shelf Life, 5, 10-20.

Owusu Apenten, R. K., \& Zhu, Q.-H. (1996). Interfacial parameters for selected Spans and Tweens at the hydrocarbon-water interface. Food Hydrocolloids, 10(1), 27-30.

Perdones, Á., Chiralt, A., \& Vargas, M. (2016). Properties of filmforming dispersions and films based on chitosan containing basil or thyme essential oil. Food Hydrocolloids, 57, 271-279.

Petersen, K., Væggemose Nielsen, P., Bertelsen, G., Lawther, M., Olsen, M. B., Nilsson, N. H., \& Mortensen, G. (1999). Potential of biobased materials for food packaging. Trends in Food Science and Technology, 10(2), 52-68.
Pinheiro, A. C., Bourbon, A. I., Quintas, M. A. C., Coimbra, M. A., \& Vicente, A. A. (2012). K-carrageenan/chitosan nanolayered coating for controlled release of a model bioactive compound. Innovative Food Science and Emerging Technologies, 16, 227-232.

Ramos, M., Beltrán, A., Peltzer, M., Valente, A. J. M., \& Garrigós, M. d. C. (2014). Release and antioxidant activity of carvacrol and thymol from polypropylene active packaging films. LWT - Food Science and Technology, 58(2), 470-477.

Requena, R., Vargas, M., \& Chiralt, A. (2018). Obtaining antimicrobial bilayer starch and polyester-blend films with carvacrol. Food Hydrocolloids, 83, 118-133.

Rhim, J. W., Mohanty, K. A., Singh, S. P., \& Ng, P. K. W. (2006). Preparation and properties of biodegradable multilayer films based on soy protein isolate and poly(lactide). Industrial and Engineering Chemistry Research, 45(9), 3059-3066.

Ribeiro, C., Vicente, A. A., Teixeira, J. A., \& Miranda, C. (2007). Optimization of edible coating composition to retard strawberry fruit senescence. Postharvest Biology and Technology, 44(1), 63-70.

Sapper, M., \& Chiralt, A. (2018). Starch-based coatings for preservation of fruits and vegetables. Coatings, 8(5).

Sapper, M., Bonet, M., \& Chiralt, A. (2019). Wettability of starch-gellan coatings on fruits, as affected by the incorporation of essential oil and/or surfactants. Lwt, 116(March), 108574.

Siracusa, V. (2012). Food packaging permeability behaviour: a report. International Journal of Polymer Science, 2012(i), 1-11.

Souza, M. P., Vaz, A. F. M., Costa, T. B., Cerqueira, M. A., De Castro, C. M. M. B., Vicente, A. A., \& Carneiro-da-Cunha, M. G. (2018). Construction of a biocompatible and antioxidant multilayer coating by layer-by-layer assembly of $\mathrm{K}$-carrageenan and quercetin nanoparticles. Food and Bioprocess Technology, 11(5), 1050-1060.

Tampau, A., González-Martínez, C., \& Chiralt, A. (2018). Release kinetics and antimicrobial properties of carvacrol encapsulated in electrospun poly-( $\varepsilon$-caprolactone) nanofibres. Application in starch multilayer films. Food Hydrocolloids, 79, 158-169.

Tampau, A., González-Martínez, C., \& Chiralt, A. (2020). Polyvinyl alcohol-based materials encapsulating carvacrol obtained by solvent casting and electrospinning. Reactive and Functional Polymers, 153(April), 104603.

Turek, C., \& Stintzing, F. C. (2013). Stability of essential oils: a review. Comprehensive reviews in food science and food safety, 12(1), 40-53.

Zhu, Y., Gao, C., Liu, X., \& Shen, J. (2002). Surface modification of polycaprolactone membrane via aminolysis and biomacromolecule immobilization for promoting cytocompatibility of human endothelial cells. Biomacromolecules, 3(6), 1312-1319.

Zhu, Y., Gao, C., Liu, X., He, T., \& Shen, J. (2004). Immobilization of biomacromolecules onto aminolyzed poly(L-lactic acid) toward acceleration of endothelium regeneration. Tissue Engineering, 10(12), 53-61.

\section{Further Reading}

http://polymerdatabase.com/Films/Multilayer\%20Films.html (page accessed in October 2019b).

www.natureworksllc.com/What-is-Ingeo/How-Ingeo-is-Made (page accessed in May 2019a).

Publisher's Note Springer Nature remains neutral with regard to jurisdictional claims in published maps and institutional affiliations. 